\title{
Endoscopic Sphincterotomy in Pregnancy
}

Endoscopic sphincterotomy may be required during pregnancy in order to treat biliary obstruction. However, the safety of therapeutic ERCP during pregnancy is still controversial, with fetal exposure to potentially harmful ionizing radiation being the main problem of this endoscopic procedure $(1,2)$. All possible steps to prevent fetal injury should therefore be taken. Only two cases have been reported in which endoscopic management of common bile duct stones was carried out during pregnancy. One procedure was 

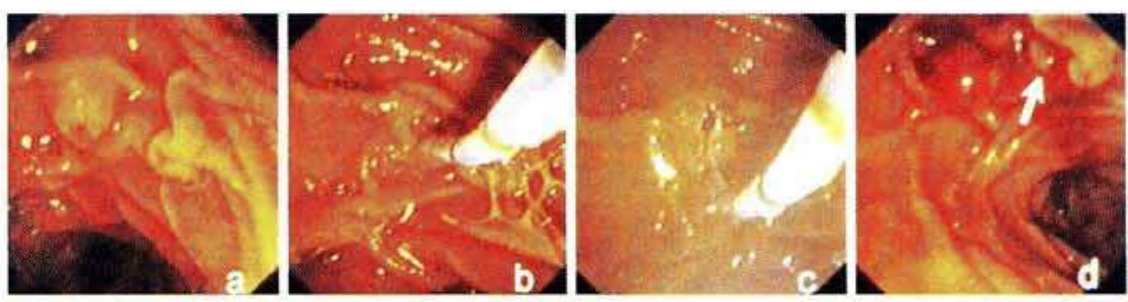

Figure 1: Normal papilla without inflammatory changes (a). Deep cannulation was achieved using a sphincterotome (b). Evidence of bile in the catheter after aspiration confirms that the common bile duct has been selectively cannulated. Endoscopic sphincterotomy (c) and stone retrieval using a Dormia basket (d) were carried out. One stone can be seen entering the duodenum (arrow)

carried out under ultrasound guidance (3), and the other without the use of fluoroscopy or other imaging techniques (4). We have carried out sphincterotomy without radiography during pregnancy in two patients.

Two women in the third trimester of pregnancy were admitted to our gastrointestinal unit. The first patient had abdominal pain, fever, and jaundice. Biochemical data showed cholestasis and leukocytosis, and the ultrasound examination showed a dilated common bile duct with stones in the gallbladder and duct. The second patient had abdominal pain radiating into the back, nausea, and repeated vomiting, and the laboratory data showed cholestasis and an elevation of pancreatic enzyme activity (serum amylase and lipase concentrations). Abdominal ultrasound also indicated stones in the gallbladder and common bile duct. In both cases, evidence of bile in the catheter during aspiration after deep cannulation enabled us to confirm that selective common bile duct cannulation had been achieved, without radiographic control (Figure 1). Endoscopic sphincterotomy was carried out with a papillotome, and stone extraction was achieved with three passes of the basket. Two and three stones, respectively, were removed into the duodenum. Both patients have done well since, with the cholangitis and pancreatitis having resolved, and ultrasonographic control showed an absence of stones in the common bile duct in both. Delivery was unproblematic, and laparoscopic cholecystectomies were carried out five and six months later, respectively.

Endoscopic sphincterotomy is indicated in the treatment of patients with acute pancreatitis and cholangitis. Since the condition of these patients may deteriorate unpredictably soon after admission, the procedure should be carried out as early as possible (5). In our patients, the aspiration of bile after deep cannulation enabled us to confirm that selective common bile duct cannulation had been achieved, allowing endoscopic sphincterotomy to be carried out without radiographic control. We consider that with this approach, the risk involved in papillotomy is much lower than the risk of fetal radiation exposure.

J. Llach, J. M. Bordas, A. Ginès, F. Mondelo, J. Terés

Digestive Endoscopy and Gastroenterology Service, Clinic I

Provincial Hospital, Barcelona, Spain

\section{References}

1. Axelrad AM, Fleischer DE, Strack LL, et al, Performance of ERCP for symptomatic choledocholithiasis during pregnancy: techniques to increase safety and improve patient management. Am J Gastroenterol 1994; 89: 109-12.

2. Siegel JH, Cohen SA. ERCP in a pregnant patient. Am J Gastroenterol 1994; 89: 1596-7.

3. Parada AA, Goncalves MDL, Tafrer E, et al. Endoscopic papillotomy under ultrasonographic control. Int Surg 1991; 6: $75-6$.

4. Zágoni T, Tulassay Z. Endoscopic sphincterotomy without fluoroscopic control in pregnancy. Am J Gastroenterol 1995; 90: 1028.

5. Fan ST, Lai ECS, Mok FPT, et al. Early treatment of acute biliary pancreatitis by endoscopic papillotomy. N Engl J Med 1993; 328: $228-32$.

Corresponding Author

J. M. Bordas, M.D.

Sección de Endoscopia Digestiva

Hospital Clinic

Villaroel 170

08036 Barcelona 